\title{
Association of serum sialic acid concentration with diabetic complications and cardiovascular risk factors in an Indian population
}

Pankaj Bansal ${ }^{1}$, Puja Bansal ${ }^{2}$, Rajesh Verma ${ }^{3}$

\author{
${ }^{1}$ Department of Medicine, School of Medical Sciences and Research, Sharda \\ University, Greater Noida, India \\ 2Department of Oral Pathology, School of Dental Sciences, Sharda University, \\ Greater Noida, India \\ ${ }^{3}$ Department of Medicine, MGM Medical College, Indore, India
}

Submitted: 18 February 2021

Accepted: 24 March 2021

Arch Med Sci Atheroscler Dis 2021; 6: e14-e17

DOI: https://doi.org/10.5114/amsad.2021.105142

Copyright (c) 2021 Termedia \& Banach

\begin{abstract}
Introduction: Sialic acid (SA) is an acetylated product of neuraminic acid. It acts as a cofactor of many cell surface receptors (e.g. insulin receptors) and is positively associated with most of the serum acute phase reactants. Sialic acid is an important component of serum, which is elevated in diseases such as diabetes and certain malignancies. Diabetes mellitus (DM) is associated with an increase in SA concentration along with other complications. The present study was undertaken to assess the relationship between serum SA and type 2 diabetes.

Material and methods: A total of 200 type 2 DM patients, 145 males and 55 females, were included in the study. Also, 100 healthy individuals served as the control group. Parameters assessed included serum SA, lipid profile, urine microalbumin, LDL-C, lipoprotein(a), and serum fibrinogen. The relationship between serum SA and diabetic complications viz retinopathy, nephropathy, and neuropathy was also assessed.

Results: Type 2 DM patients had significantly higher levels $(p<0.01)$ of SA $(77.35$ $\pm 4.6 \mathrm{mg} \%)$ as compared to the control group $(68.23 \pm 7.9 \mathrm{mg} \%)$. Increased levels of serum SA were seen in patients with diabetic nephropathy and retinopathy. No correlation was seen between serum SA and diabetic neuropathy.

Conclusions: Elevated serum SA concentration is significantly related to type $2 \mathrm{DM}$ and associated cardiovascular risk factors. Further study of acute-phase response markers and mediators as indicators or predictors of diabetic microvascular complications is therefore justified.
\end{abstract}

Key words: serum sialic acid, diabetes, cardiovascular.

\section{Introduction}

Diabetes mellitus, the most common, serious, chronic endocrine disease, is characterized by hyperglycaemia, metabolic abnormalities, and long-term complications involving the eyes, kidneys, nerves, and blood vessels. It has become a major health problem worldwide, reaching epidemic proportions in many developing countries as well as in minority groups in the developed world [1].

Sialic acid (SA), a generic term for a family of acetylated derivatives of neuraminic acid, is an essential component of glycoproteins and gly-

\author{
Corresponding author: \\ Dr. Pankaj Bansal \\ Department of Medicine \\ School of Medical \\ Sciences and Research \\ Sharda University \\ Greater Noida, India \\ E-mail: profpankajbansal@ \\ gmail.com
}


colipids. It acts as a cofactor of many cell surface receptors (e.g. insulin receptors) and is positively associated with most serum acute phase reactants [2]. Sialic acid is an important component of serum that is elevated in diseases such as diabetes and certain malignancies. Diabetes mellitus is associated with an increase in SA concentration along with other complications [3]. In a prospective study, Linderberg et al. found that serum sialic acid (SSA) concentration was a strong predictor of cardiovascular disease (CVD) mortality [4].

In the present study, the relationship between SA concentration and type II diabetes (DM) was investigated. Moreover, we looked for a correlation between SSA and clinically relevant parameters such as blood glucose, lipid profile (serum triglycerides and total cholesterol), urine microalbumin, LDL-C, lipoprotein (a), serum fibrinogen, habit of smoking, hypertension, fasting blood glucose, and glycated haemoglobin $\left(\mathrm{HbA}_{1 \mathrm{c}}\right)$ in type II diabetic patients. We also attempted to show whether these indices could serve as risk factors for CVD. The relationship between SSA and diabetic complications viz retinopathy, nephropathy, and neuropathy was also assessed.

\section{Material and methods}

The study included 200 type 2 DM patients (Group A), 145 males and 55 females. Also, 100 healthy individuals (Group B) served as the control group, who were matched for age, sex, and body mass index. Diabetic patients were defined as those who had known diabetes (onset of DM after 40 years of age), and those with fasting plasma glucose value $\geq 126 \mathrm{mg} \%$ on 2 occasions. All group $B$ subjects underwent an oral glucose tolerance test (OGTT) to exclude the presence of impaired glucose tolerance (IGT), according to WHO criteria. A history of smoking habit and hypertension was also recorded for all the subjects.

After overnight fasting, venous blood samples for blood glucose and lipid profile estimation were obtained by venipuncture from an antecubital vein without stasis. $\mathrm{HbA}_{1 \mathrm{c}}$, urine microalbumin, $\mathrm{LDL}-\mathrm{C}$, serum fibrinogen, lipoprotein (a), blood pressure, and SSA were determined for all the subjects.

Hypertension was defined as a blood pressure $>140 / 90 \mathrm{~mm} \mathrm{Hg}$ or the subject taking antihypertensive medication. Retinopathy was assessed from photographs of two retinal fields per eye, graded by a single observer.

Blood was collected and the serum was separated, centrifuged, and stored at $-70^{\circ} \mathrm{C}$. SSA was estimated using cysteine hydrochloride. In the method of Winzler, a protein precipitate of serum containing SA reacts with diphenylamine, producing a purple colour, which is quantitatively measured in a spectrophotometer at $530 \mathrm{~nm}$.

\section{Statistical analysis}

Data was given as mean \pm standard deviation (SD) and Student's $t$-test for impaired data and $p$-value were used for the statistical evaluation.

\section{Results}

The type 2 diabetic patients had higher levels $(p<0.01)$ of SA $(77.35 \pm 4.6 \mathrm{mg} \%)$ in comparison with controls (68.23 $\pm 7.9 \mathrm{mg} \%)$. The comparison is also illustrated in Table I.

Elevated SSA concentrations were also significantly associated with several risk factors for cardiovascular disease like triglyceride (TG), cholesterol, lipoprotein (a), LDL-C, hypertension, hyperfibrinogenaemia, and smoking in the type II diabetic subjects (Table II). Increased levels of SSA were seen in patients with diabetic nephropathy and retinopathy. No correlation was seen in between SSA and diabetic neuropathy (Table III).

\section{Discussion}

In the last few years, different workers all over the world have demonstrated that the concentration of SA in the human serum is abnormally high in a number of pathological states where the underlying pathology is either of tissue destruction,

Table I. Comparison of various metabolic parameters between type 2 diabetic patients and control group

\begin{tabular}{|lcc|}
\hline Parameters & $\begin{array}{c}\text { Type 2 DM } \\
\text { (group A) }\end{array}$ & $\begin{array}{c}\text { Control group } \\
\text { (group B) }\end{array}$ \\
\hline Fasting blood glucose [mg\%] & $178 \pm 9.6$ & $93 \pm 5.2$ \\
\hline Glycosylated haemoglobin $\left(\mathrm{HbA}_{1 \mathrm{c}} \%\right.$ ) & $7.1 \pm 2.5$ & $4.0 \pm 9.1$ \\
\hline Sialic acid [mg\%] & $77.35 \pm 4.6$ & $68.23 \pm 7.9^{* *}$ \\
\hline Triglycerides [mg\%] & $247 \pm 1.3$ & $101 \pm 3.4$ \\
\hline Total cholesterol [mg\%] & $262 \pm 4.6$ & $150 \pm 0.4$ \\
\hline LDL-C [mg/dl] & $159.06 \pm 1.3$ & $75.22 \pm 4.7$ \\
\hline Urine microalbumin [mg/gm creatinine] & $184.20 \pm 6.5$ & $20.79 \pm 2.6$ \\
\hline Lipoprotein (a) [mg/dl] & $53.23 \pm 2.2$ & $16.42 \pm 1.2$ \\
\hline Values are presented as mean $\pm S D$ for group $A$ and $B .{ }^{* *} p<0.01$. &
\end{tabular}


Table II. Relationship between SSA and various parameters in type 2 diabetic patients

\begin{tabular}{|c|c|c|c|}
\hline Parameter & & Mean SSA [mg\%] & $P$-value \\
\hline \multirow[t]{2}{*}{ Smoking } & Diabetic smokers & $74.32 \pm 1.8$ & \multirow[t]{2}{*}{$<0.05$} \\
\hline & Diabetic non-smokers & $68.25 \pm 1.2$ & \\
\hline \multirow[t]{2}{*}{ Hypertension } & Hypertensive diabetics & $74.24 \pm 4.2$ & \multirow[t]{2}{*}{$<0.05$} \\
\hline & Non-hypertensive diabetics & $68.66 \pm 2.3$ & \\
\hline \multirow[t]{2}{*}{ Hyperfibrinogenaemia } & Present & $73.19 \pm 8.3$ & \multirow[t]{2}{*}{$<0.05$} \\
\hline & Absent & $67.61 \pm 0.8$ & \\
\hline \multirow[t]{2}{*}{ Lipoprotein(a) } & Abnormally increased & $74.54 \pm 1.6$ & \multirow[t]{2}{*}{$<0.01$} \\
\hline & Within normal limits & $68.84 \pm 2.3$ & \\
\hline \multirow[t]{2}{*}{ Triglycerides } & Abnormally increased & $73.13 \pm 1.3$ & \multirow[t]{2}{*}{$<0.01$} \\
\hline & Within normal limits & $67.02 \pm 2.8$ & \\
\hline \multirow[t]{2}{*}{ Total cholesterol } & Abnormally increased & $73.07 \pm 1.2$ & \multirow[t]{2}{*}{$<0.01$} \\
\hline & Within normal limits & $64.15 \pm 8.3$ & \\
\hline \multirow[t]{2}{*}{ LDL-C } & Abnormally increased & $74.28 \pm 6.2$ & \multirow[t]{2}{*}{$<0.001$} \\
\hline & Within normal limits & $64.77 \pm 1.5$ & \\
\hline \multirow[t]{2}{*}{ Urine microalbumin } & Abnormally increased & $74.16 \pm 6.4$ & \multirow[t]{2}{*}{$<0.001$} \\
\hline & Within normal limits & $65.51 \pm 0.5$ & \\
\hline
\end{tabular}

Table III. Serum sialic acid levels in type 2 diabetes with nephropathy and retinopathy

\begin{tabular}{|lccccc|}
\hline Parameter & $\begin{array}{c}\text { Diabetes without } \\
\text { any complications }\end{array}$ & $\begin{array}{c}\text { Diabetic } \\
\text { nephropathy }\end{array}$ & $\begin{array}{c}\text { Diabetic } \\
\text { retinopathy }\end{array}$ & $\begin{array}{c}\text { Diabetic } \\
\text { neuropathy }\end{array}$ & $\begin{array}{c}\text { Non-diabetic } \\
\text { subjects }\end{array}$ \\
\hline Serum sialic acid [mg\%] & $71.09 \pm 8.67^{*}$ & $74.32 \pm 1.4^{\star * *}$ & $72.28 \pm 3.2^{\star *}$ & $68.45 \pm 0.3^{\phi}$ & $66.25 \pm 7.1$ \\
\hline
\end{tabular}

Values are presented as mean $\pm S D .{ }^{*} p<0.05,{ }^{* *} p<0.01,{ }^{* * *} p<0.001,{ }^{\phi} p<0.5$.

tissue proliferation, depolymerization, or inflammation [5]. Sialic acid is a terminal component of the non-reducing end of carbohydrate chains of glycoproteins and glycolipids [6].

The steps by which type 2 DM causes atherosclerotic vascular disease are not clear. Emphasis is shifting from elucidation of risk factors, such as insulin resistance, to an understanding of the process occurring at the vasculature (Playford and Watts, 1999). An increase in the concentration of SSA has been shown to be a possible cardiovascular risk factor in patients with non-insulin-dependent diabetes (Crook et al., 1993) [7].

The results of our study showed increased serum SA concentration $(p<0.01)$ in type 2 diabetics, as compared to normal control subjects. Our results were compared with other studies, which reported similar findings. Yilmaz et al. found significantly increased levels of SSA and thiobarbituric acid reactive substances in subjects with type 2 DM [8]. Ekin et al. [9, 10] and Abdella et al. [11] also reported higher SA levels in diabetics compared to those of controls.

The higher SSA level in diabetic patients is explained by the high level of serum acute phase proteins, known to be present in both type 1 and type $2 \mathrm{DM}$. Abnormalities of red blood cell membrane in diabetic patients, with subsequent release of SA, were also found to be yet another contributing factor to increased SSA levels in diabetic patients [4]. Inflammatory markers have been related to the development of diabetes in adults, supporting the hypothesis that an inflammatory component is involved in its pathogenesis. Sriharan et al. reported increased TSA levels in patients with previous GDM [12].

Furthermore, we found that the serum SA levels correlated with the degree of metabolic control (as estimated by $\mathrm{HbA}_{1 \mathrm{C}}$ ). The association between $\mathrm{SA}$ and $\mathrm{HbA}_{1 \mathrm{c}}$ most likely follows from the association between SA and microvascular complications, which are well established to be related to glycaemic control and diabetes duration [13].

Besides this, serum SA levels have been reported to increase in type $1 \mathrm{DM}$ patients with albuminuria $[6,11,14]$. We found higher SSA levels in diabetics with increased urinary microalbuminuria. Patients with insulin-dependent diabetes mellitus (IDDM) and albuminuria have been reported to have highly increased cardiovascular morbidity and mortality [15].

Links between SA and risk factors for vascular disease, such as blood lipids (Wakabayashi et al., 1992), smoking (Lindberg et al., 1991), hyperfibrinogenaemia (Crook et al., 1996), and lipoprotein (Kario et al., 1994), have been reported [16]. We found similar results in our study. Significant correlation was seen between SSA levels and CVD risk factors such as LDL-C, hypertension, diabetic retinopathy, and nephropathy. In patients with 
CVD, an increase in SSA level may be due to the release of free and bound SA from damaged myocardial cells or vascular endothelium [4]. Serum sialic acid is considered as a marker of innate immunity, and activated innate immunity is a risk factor for cardiovascular disease mortality in type 2 diabetes. Masuda et al. have shown that SSA reflects the status of blood glucose control and the progression of ischaemic disease of the lower extremities in NIDDM. Zahedi et al. have found that it increased post prandially giving further insight as to why it is considered to be a cardiovascular risk factor [17]. According to Soedamah-Muthu et al., SA and fibrinogen are strong predictors of CHD in men with type 1 diabetes, beyond the effect of established risk factors [18]. Nayak et al. even recommended measurement of SA, microalbumin, and waist-to-hip ratio along with the blood pressure for all type 2 diabetic patients, to assess the cardiovascular risk [14].

In conclusion, we have found a significant association between SSA concentrations and type 2 diabetes patients and associated cardiovascular risk factors. It will now be important to investigate the relationship between SA and/or other markers and mediators of the acute-phase response (e.g. proinflammatory cytokines) and the development or progression of diabetic microangiopathy.

\section{Conflict of interest}

The authors declare no conflict of interest.

\section{References}

1. Gul A, Rahman MA. Changes in glycosylated proteins in diabetic and non-diabetic patients with and without cardiovascular complications. Asia Pacific J Clin Nutr 2003; 12: 277-81.

2. Sabzwari MJ, Ahmad M, Majeed MT. Serum sialic acid concentration and type II diabetes mellitus. Prof Med J 2006; 13: 508-10.

3. Inayat-ur-Rahman, Malik SA, Bashir M, Khan R, Iqbal M. Serum sialic acid changes in non-insulin-dependant diabetes mellitus (NIDDM) patients following bitter melon (Momordica charantia) and rosiglitazone (Avandia) treatment. Phytomedicine 2009; 16: 401-5.

4. Merat A, Arabsolghar R, Zamani J, Roozitalabet MH. Serum levels of sialic acid and neuraminidase activity in cardiovascular, diabetic and diabetic retinopathy patients. Iran J Med Sci 2003; 28: 123-6.

5. Hangloo VK, Kaul I, Zargar HU. Serum sialic acid levels in healthy individuals. J Postgrad Med 1990; 36: 140-2.

6. Kurtoğlu S, Atabek ME, Muhtaroglu S, Keskin M. The association of serum total sialic acid/total protein ratio with diabetic parameters in young type 1 diabetic patients. Acta Diabetol 2006; 43: 1-5.

7. Muniandy S, Qvist R, Zaini A, Chinna K, Ismail IS. A re-evaluation of plasma sialic acid determination using the periodate resorcinol method versus the enzymatic method. Southeast Asian J Trop Med Public Health 2005; 36: 1011-3.
8. Yilmaz G, Yilmaz FM, Aral Y, Yucel D. Levels of serum sialic acid and thiobarbituric acid reactive substances in subjects with impaired glucose tolerance and type 2 diabetes mellitus. J Clin Lab Anal 2007; 21: 260-4.

9. Ekin S, Mert N, Gunduz H, Meral I. Serum sialic acid levels and selected mineral status in patients with type 2 diabetes mellitus. Biol Trace Elem Res 2003; 94: 193-201.

10. Ekin S, Meral I, Gunduz H, Mert N. Comparative study of total protein, and total and lipid-associated serum sialic acid levels in patients with type 2 diabetes mellitus. J Clin Lab Anal 2003; 17: 124-6.

11. Abdella N, Akanji AO, Mojiminiyi OA, Assoussi AA, Moussa M. Relation of serum total sialic acid concentrations with diabetic complications and cardiovascular risk factors in Kuwaiti type 2 diabetic patients. Diabetes Res Clin Pract 2000; 50: 65-72.

12. Sriharan M, Reichelt AJ, Opperman MLR, et al. Total sialic acid and associated elements of the metabolic syndrome in women with and without previous gestational diabetes. Diabetes Care 2002; 25: 1331-5.

13. Crook MA, Pickup JC, Lumb PJ, et al. Relationship between plasma sialic acid concentration and microvascular and macrovascular complications in type 1 diabetes. Diabetes Care 2001; 24: 316-22.

14. Nayak BS, Duncan H, Lalloo S, et al. Correlation of microalbumin and sialic acid with anthropometric variables in type 2 diabetic patients with and without nephropathy. Vasc Health Risk Manag 2008; 4: 243-7.

15. Yokoyama H, Jensen JS, Jensen T, Deckert T. Serum sialic acid concentration is elevated in IDDM especially in early diabetic nephropathy. J Intern Med 1995; 237: 519-23.

16. Wang B, Brand-Miller J. The role and potential of sialic acid in human nutrition. Eur J Clin Nutr 2003; 57: 1351-69.

17. Nigam PK, Narain VS, Kumar A. Sialic acid in cardiovascular diseases. Indian J Clin Biochem 2006; 21: 54-61.

18. Soedamah-Muthu SS, Chaturvedi N, Pickup JC, Fuller JH; EURODIAB Prospective Complications Study Group. Relationship between plasma sialic acid and fibrinogen concentration and incident micro- and macrovascular complications in type 1 diabetes. The EURODIAB Prospective Complications Study (PCS). Diabetologia 2008; 51: 493-501. 